\title{
Use of Collective Expertise as a Tool to Reinforce Food Safety Management in Africa
}

Didier Montet ${ }^{1}$, Jamal Eddine Hazm ${ }^{2}$, Abdelouahab Ouadia ${ }^{3}$, Abdellah Chichi ${ }^{4}$, Mame Samba Mbaye ${ }^{5}$, Michel Bakar Diop ${ }^{6}$, Paul Mobinzo Kapay ${ }^{7}$, Apollinaire Biloso ${ }^{8}$, Isaac M. Diansambu ${ }^{9}$, Corinne Teyssier ${ }^{1}$, Joel Scher ${ }^{10}$, Marie Louise Scippo ${ }^{11} \&$ Maria Teresa Barreto Crespo ${ }^{12,13}$

${ }^{1}$ Qualisud, Univ Montpellier, CIRAD, Montpellier SupAgro, Univ d'Avignon, Univ de La Réunion, Montpellier, France

${ }^{2}$ Faculté des Sciences et Techniques, University Sidi Mohammed Ben Abdellah, Fès, Morocco

${ }^{3}$ Laboratoire Aliments-Environnement-Santé, Faculté des Sciences et Techniques, University Cadi Ayyad, Marrakech, Morocco

${ }^{4}$ Biotechnologies \& Génie des Biomolécules, Faculté des Sciences et Techniques de Tanger, Tanger, Morocco

${ }^{5}$ Faculté des Sciences et Techniques, University Cheikh Anta Diop de Dakar, Dakar-Fann, Senegal

${ }^{6}$ UFR des Sciences Agronomiques de l'Aquaculture et des Technologies Alimentaires, University Gaston Berger, Saint-Louis, Senegal

${ }^{7}$ University of Lubumbashi, Faculté de Médecine Vétérinaire, Lubumbashi, Democratic Republic of Congo

${ }^{8}$ University of Kinshasa, Faculté des Sciences Agronomiques, Kinshasa, Democratic Republic of Congo

${ }^{9}$ ERAIFT, Campus UNIKIN, Kinshasa Lemba, Democratic Republic of Congo

${ }^{10}$ LIBio - ENSAIA, Vandoeuvre, France

${ }^{11}$ University of Liège, Département des Sciences des Denrées alimentaires, Liège, Belgique

${ }^{12}$ iBET, Instituto de Biologia Experimental e Tecnológica, Oeiras, Portugal

${ }^{13}$ Instituto de Tecnologia Química e Biológica António Xavier, Universidade Nova de Lisboa, Oeiras, Portugal

Collaborators from EU: Alain Duperet, ENSG Champs-sur-Marne, France; Jean-Paul Rudant, NSG Champs-sur-Marne, France; Giuseppina Carra, University of Catania, Italy; Philippe Lepoivre, Liege University, Belgium; Vincent Dollé \& Erol Külahci, AUF Bruxelles.

Collaborators from Morocco: UAE Tanger - Hassan Er-raoui \& Maryam El Bakkali, UCA Marrakech - Aouatif Aboudia, Mustapha Barakate, Mohamed Benichou, Brahim Mimouni; USMBA Fès - Mustapha Ijjaali, Abdelrhani Elachqar, Amina Bousetta, Rajae Belkhou, \& Sanae Lairini.

Collaborators from Senegal: UCAD Dakar - Nicolas Ayessou, Ndior Mathilde Cabral, Mady Cissé, Modou Absa Dieng, Aboubacry Kané, Ibrahima Mall, Malick Mbengue, Ndiaye Adiara, Adama Diakhère Ngom, Oureye Mame Sy \& Samba Ndao Sylla; UGB Saint Louis - Amadou Bocar Bal; other institutions - Cheikh Sall, ISRA/CNERV; Sokhna Ndao Diao, CN Codex Alimentaire, Safietou Sabaly, Bureau de Contrôle Qualité, DPV, Wedji Fall, BIOSCOPE, Moussa Kassé, Kasper Consulting, Néné Gallé Ba, ITA \& Samba Diao Ba, DPV.

Collaborators from Democratic Republic of Congo: UNILU Lubumbashi - Gilbert Kishiba Fitula (Recteur), César Nkuku Khonde, Victor Okombe Embeya, Mireille Kitwa Umba, Lucien Nyembo Kimuni, Florence Kampemba Mujinga, Olivier Bomolo, Auguste, Chocha, John Tshomba, Mukalay Abdon, Joe Kahumba, \& Richard Mukendi; UNIKIN Kinshasa - Banza Somwe \& Biloso Moyene; ERAIFT Kinshasa - Isaac Diansambu \& Michel Baudouin; other institutions - Emile Mota, UNILU, Parlement National, Ministre honoraire de l'Agriculture, Léa Mobiala, Ministère de l'agriculture, pêche et élevage, Didiert Tshikung, Représentant du Ministre Provincial de l'Éducation du Gouvernement Provincial du Haut-Katanga \& Tresor Kanyangala Représentant du Ministre Provincial de la Santé du Gouvernement Provincial du Haut-Katanga.

Correspondence: Didier Montet, UMR 95 QualiSud/Cirad/University of Montpellier, TA B-95 /16, 73 rue J-F Breton, 34398 Montpellier cedex 5, France. E-mail: didier.montet@cirad.fr

Received: February 20, $2020 \quad$ Accepted: March 26, $2020 \quad$ Online Published: April 14, 2020

doi:10.5539/jfr.v9n3p9

URL: https://doi.org/10.5539/jfr.v9n3p9 


\begin{abstract}
The Erasmus+ project (2017-2020) entitled Societal Challenges and Governance of African Universities: the case of ALIments in Morocco, the Democratic Republic of the Congo and Senegal (DAfrAli) seeks to strengthen the governance capacity of African Higher Education Institutions to mobilize their resources in order to respond to major societal challenges in relation to external stakeholders. A work package consisted of organizing three workshops to use Collective Expertise as a tool for the identification of societal risks, in the area of food safety. These three workshops were conducted in Morocco, in Senegal and in Democratic Republic of Congo. The exercise was performed by country academics with the contribution of the European project partners.

Collective Expertise gave results that demonstrated that, with a careful and diversified selection of experts, this methodology can have a deep importance to list the food hazards in a country. The results obtained can induce changes in university curricula, showed the social impacts of food safety, unveiled research needs and training needs for different agents in the food sector and above all the impact in food policy in a country. The collective expertise approach of the determination of hazards also permitted to discuss possible organization models for food risk management in the 3 countries.
\end{abstract}

Keywords: Africa, food safety, collective expertise, food safety management, food safety education and training

\title{
1. Introduction
}

Unsafe food continues to be one of the major causes of death in low- and middle-income countries. To mitigate food safety issues, many aspects have to be addressed, many of them are related to financial causes, but other causes can be identified as revised by Montet et al. (2019). These authors proposed a methodology that could be used for countries that do not have yet a strong food safety control system, namely African countries. That methodology was called Collective Expertise and was proposed to be used as a tool for knowledge translation into supported decisions in terms of food safety. It enables the transfer of the knowledge already existing in local universities, private companies, citizen's organizations, to the authorities involved in managing food safety, which would help to develop local strategies to face the challenges of food safety and food security and to solve problems. Collective Expertise was tested in the scope of the Erasmus+ project (European Union) entitled "Societal Challenges and Governance of African Universities: the case of ALIments (food) in Morocco, the Democratic Republic of the Congo and Senegal (DAfrAli)". This project sought to strengthen the governance capacity of African Higher Education Institutions to mobilize their resources in order to respond to major societal challenges in relation to external stakeholders. In that project, three different African countries were partners, each of them with very different approaches and capacities to solve problems related to the food safety hazards.

\section{Theory}

When a country does not have a national food safety system, i.e. a food safety agency capable of assessing health risks related to local hazards (biological and chemical), it is still possible to create expert committees composed of local specialists who can easily by their knowledge assess the risks and advise decision-makers on the measures to take (withdrawal, prohibition, fines...). A decision-maker is the official person who has the political force to make decisions and as such impact on the health of the population. The expert committee pieces of advices or recommendations will permit to decision-maker to have effective, rapid prevention or withdrawal actions proportional to the hazards. In addition, this system is inexpensive. It also makes it possible to implement an action in certain local social conditions without expensive and difficult to handle equipment.

We hypothesized that the country expert groups would produce valuable information on food hazards in two days rather than depending on costly comprehensive systematic studies.

\section{Methodology of the Collective Expertise}

Collective Expertise was used as an experimental methodology for the three mentioned African countries that have different approaches and developments of safety control systems.

Collective Expertise consists of collecting and highlighting available information shared by experts working, for instance in the field of food safety in the universities and agencies, private companies and other stakeholders. A paper describing this methodology was published by the same group of authors in the framework of the same Erasmus project 2019 (Montet et al., 2019). These experts have their different scientific and technical backgrounds and have an accurate idea of the state of food safety in their own country. The results, in the form of a collective report, obtained by such a panel can represent for authorities a source of technical advices of interest for the decision concerning the national food hazards with minimal costs (Montet et al., 2019). The coordinator of this work and some co-authors experimented this methodology in Bangkok, Thailand in 2010 in order to 
identify the topics of common interest for European and South-East Asian partners in the thematic "Food Quality, Safety and Traceability" towards a strengthening of Science and Technology collaboration between SE Asia and EU in the FP7 programmes (Montet et al., 2010). They did the same in Egypt to answer to a demand of the French Embassy and produced a paper that permitted to identify the future topics of common interest for EU and Egypt in food quality, safety and traceability (Montet et al., 2015).

A work package of the Erasmus+ project consisted of organizing three workshops for the identification of societal hazards related to food safety. These workshops were conducted at the Sidi Mohammed Ben Abdellah University of Fez (Morocco), at the Cheikh Anta Diop University of Dakar (Senegal) and at the University of Lubumbashi (Democratic Republic of Congo). The objectives of the workshops were to identify food safety hazards in the respective countries, and to translate the selected food safety hazards into identifying the skills needed to prefigure the construction of university curricula in this field. Additionally, participants in the workshops identified research needs, and addressed societal and training needs in their own countries. These workshops were attended by 25 to 30 participants per country. The participants belonged mainly to the teaching staff of their own university. The selection of the participants was done according to their different expertise. There was no ambition to cover all the aspects of food safety as these were the first exercises performed in the countries to test collective expertise. The rest of the participants belong to different institutions involved in food safety as Codex alimentarius in Senegal, food safety agencies in Europe, ONSSA in Morocco (see list of collaborators at the beginning of the paper). Each workshop had two days of activity. The participants were divided into two groups of experts and were asked to assess the major challenges in the areas of biological and chemical hazards. It was possible to have an idea, on how each country could use local expertise to face the challenges of food safety.

The exercise permitted to evaluate the status of the political organization of countries in the field of food safety; to consider country specific requests in assessing food hazards; produce a document containing the discussed proposals including key topics for possible cooperation between local universities and between EU and African universities.

\section{Results}

\subsection{Food Risk Management in the Three Countries}

In this Erasmus project, 3 African countries were chosen considering their very different national organizational levels in terms of food safety. This work presents the organization that was studied thanks to the experts in the three countries, from the most organized country, which is Morocco which has a national food safety agency, to the least organized one that is that of Democratic Republic of Congo (DRC), passing through the middle that is Senegal which has good universities and a structured Codex Alimentarius team that acts as the national agency.

\subsubsection{Food Risk Management in the Morocco}

Management of food safety in Morocco has adopted an approach to ensure the safety of the whole food production chain. The National Office for Food Safety (ONSSA) was established in 2009 in accordance with Law No. 25-08 (Morocco, 2009), in order to implement the Government's policy on the safety of plants, animals and food products, from raw materials to the final consumer, including animal feed. With this aim, and with the view to provide the agri-food sector with a regulatory and legal framework, Law No. 28-07 (Morocco, 2010) regulating the safety of food products in Morocco was adopted in 2010. The stipulated provisions of this Act cover all stages of the handling, processing, packaging, transportation, storage, distribution and sale or of primary products, food products for human consumption and feedstuffs. This law lays down the general principles of food and feed safety and determines the conditions under which these products may be classified as safe products, whether fresh or processed, and whatever processes and systems of preservation, processing and manufacturing are used. In addition, that law lays down general requirements for the placing on the market of only safe products by laying down the general rules on hygiene, use of cleaning and disinfecting products and thresholds and contamination in primary products, food and feed.

On the other hand, Law No. 28-07 (Morocco, 2010) establishes the rules making it mandatory for consumer information, in particular through the labelling of primary products, food products and animal feed and the determination of accompanying documents. In addition to food safety, ONSSA has to give confidence to the consumers and all its partners. Its functions and tasks in the particular sector of food safety were established as: i) To ensure the sanitary protection of national plant and animal heritage and control of plant and animal products, including fish products for import, domestic market and export; ii) To perform analysis of food risks; iii) To issue opinions regarding health compliance of sea fishing; iv) To conduct registration of veterinary medicines and establishments; v) To check food additives, packaging materials, products and materials that come into contact 
with food and fertilizers and irrigation water products; vi) To check, register and approve pesticides and vii) To monitor and certify seeds and plants.

This is already a mature system that only needs improvement in terms of collective expertise by independent experts selected in the national panel of scientists.

\subsubsection{Food Risk Management in Senegal}

Food safety is a public health priority in Senegal. International health regulations are well reflected in national policies and programs. In addition, there are efforts to support the use of standards, codes of practice and guidelines issued by the Codex Alimentarius Commission. Senegal has control mechanisms to ensure food safety and protect the health of consumers and is implementing multiple initiatives to strengthen the food safety system, namely the project of national risk assessment system and an official control system. The actual food safety management is based on national laws and decrees (Senegal, 1966; Senegal, 1983a) on the Hygiene Code, Decrees on the Control of Fishery Products, Meat, Fruits and Vegetables. However, there is no formal structure in charge of food safety coordination in Senegal, but various ministerial departments (Trade, Health, Fisheries, Agriculture, Livestock, etc.) manage the aspects of safety that concern them directly, which sometimes lead to overlaps and a lack of communication. For the control system, the competent authorities of sectoral ministries act as risk managers for food products. They build on existing laboratories at the country or international levels. The National Codex Alimentarius Committee (CNCA) was established on 24 Nov. 1983 by Decree No. 83-1204 and is under the authority of the Ministry of Health (Senegal, 1983b). An Expert Committee on Risk Assessment was created in August 2013.

The National Codex Alimentarius Committee (CNCA) carries out stakeholder training on Risk Analysis components, training of risk managers on the programming of risk-based controls, selection of experts, training of experts on risk assessment methodology, proposed structuring of a National Risk Assessment System (DNER), Structuring the INFOSAN Network (International Food Safety Authorities Network). With regard to risk assessment, the CNCA supports the authorities in setting up a National Risk Assessment System (DNER) composed of:

i) An Orientation and Oversight Council (COS) to define National Risk Assessment Unit (NRAU) strategic directions approve and ensure the implementation of its activities; ensure the proper functioning of the NRAU; carry out periodic evaluations of the action plan according to the defined objectives and propose to the competent authorities the persons responsible for coordinating the NRAU and ii). The NRAU formulates scientific opinions on referral to the supervisory or self-referral ministries, collaborates with the competent state services for the development and monitoring programs, develop an annual action plan in collaboration with the official control services, identify risk assessment priorities, implement programs and studies that respond to identified needs, encourage the dissemination of research results, set up a scientific data bank on food safety and generate food safety communication elements.

However, it remains to be seen how to consolidate the achievements with a strong will of the authorities. Senegal has to think about creating a food safety agency to complete their system, based on their list of experts and with collaboration with countries that have food safety agencies. They have also to open the official list of experts to national scientists.

\subsubsection{Food Risk Management in Democratic Republic of Congo (DRC)}

In the DRC, the area of food safety is governed by the Ministry of Public Health. It is supported by the decree-law on public health, initiated in 2001. In addition, food safety is in the service competencies of Animal and Plant Quarantine according to the Presidential Decree No 05/162 of 18 Nov 2005 on phytosanitary regulations in the DRC (DRC, 20005) and the Congolese Office of Control according to Decree No 09/44 of $03 / 12 / 2009$. This decree fixes the statutes of a public establishment of scientific and technical nature called Congolese Office of Control aiming at the evaluation of conformity through the inspection, the certification and the tests or analysis of local and/or imported food products with reference to national, regional and/or international standards (DRC, 2009).

The Animal and Plant Quarantine Service deals with for imported products by: i) Document control: import permit, sanitary and/or phytosanitary zoo certificate and certificate of origin; ii) Control itself: control of transport conditions (temperature, engine in motion to check if there has been no break in the cold chain for fresh products); iii) Control of the goods (packaging conditions, date of production and expiry); iv) Opening of the cartons for odour, colour, consistency, and v) Sample collection for laboratory analysis (verification, toxic 
substance, microbes). After $48 \mathrm{~h}$ if the results are satisfactory, the inspection issues a certificate of release for consumption and in case of doubt, several analyses are carried out in different laboratories. In case of danger, the product is destroyed or returned. In the case where the product is put into consumption, quality monitoring is provided by the urban health service of the Ministry of Agriculture.

In the DRC, the national health system is based on the knowledge of the ministries in charge of agricultural and animal products. This country does not use expertise outside the ministries and it will be difficult for it to overcome a serious health crisis.

\subsection{Analysis of Societal Challenges in Food Safety by Collective Expertise in the 3 Countries}

These 3 workshops confirmed that collective expertise could be a potent tool to address, if only partly, the major challenges in food safety. The exercise of this collective expertise made it possible to capitalize on very rich information and reflections (formalized or not) which otherwise would have remained scattered, not valued and would have fallen into oblivion.

\subsubsection{Analysis of Food Societal Challenges in Safety Hazards in Morocco}

The collective work enlightened the Moroccan universities involved in this project and their partners to have a vision on the challenges they face in the field of food safety (Table 1).

Table 1. Highlights of biological and chemical problems found by Collective Expertise in Morocco (by alphabetical order and not by degree of risk)

\begin{tabular}{ll}
\hline Biological problems & Chemical problems \\
\hline Antibiotic multi-resistant microorganisms & Anti-fouling biocides in aquaculture \\
Dairy traditional products & Chemical treatments in post-harvest of \\
Hygiene in aquaculture & fruits and vegetables \\
Hygiene in slaughterhouses and in souk & Food additives exposure for consumers \\
Hygiene in street catering and vendors & Lead migration in traditional ceramic \\
Mycotoxins in spices, grape, dried fruits and cereals Pest & Nitrites in processed meats \\
(rodents, insects... ) in processing chains & Pesticides in aquaculture \\
& Pesticides in green tea and mint \\
Packaging and labelling & \\
\hline
\end{tabular}

The analysis of biological problems has revealed serious hygiene problems, particularly in traditional enterprises, namely in the souks (shop in local market). Weekly market slaughterhouses are one of the most cited examples, as are street catering and street vendors and traditionally produced dairy products.

The control of the conditions of storage, packaging, repackaging and re-labelling of food and in particular cereals, dried fruits and spices seems to be matters to be dealt with by the competent authorities in this sector in Morocco. This could significantly reduce contamination from pests and molds that produce mycotoxins.

The analysis of chemical hazards has logically brought out a poorly controlled use of pesticides in agriculture (fruits, fresh vegetables, green tea, and mint) with an impact also on aquaculture. Insidious pollutions have been revealed by experts such as the use of anti-fouling biocides (tributyltin) in aquaculture, the migration of lead in traditional ceramics for food use or the use of nitrites in industrial sausages.

Collective Expertise allowed us not only to be aware of the most significant hazards, but also to highlight the practical approach to control and prevent them (Montet et al. 2019). Thus, the reflection on the dangers was made also through the methodologies necessary to their control. The field of experience of teachers-researchers necessarily impact the reflection. In order to be a societal challenge, a hazard must crosscut a commonly consumed food and therefore present a risk for a large section of the population or at least have significant direct economic consequences. Figure 1 reflects some of the mitigation possibilities for the problems identified the societal areas. 


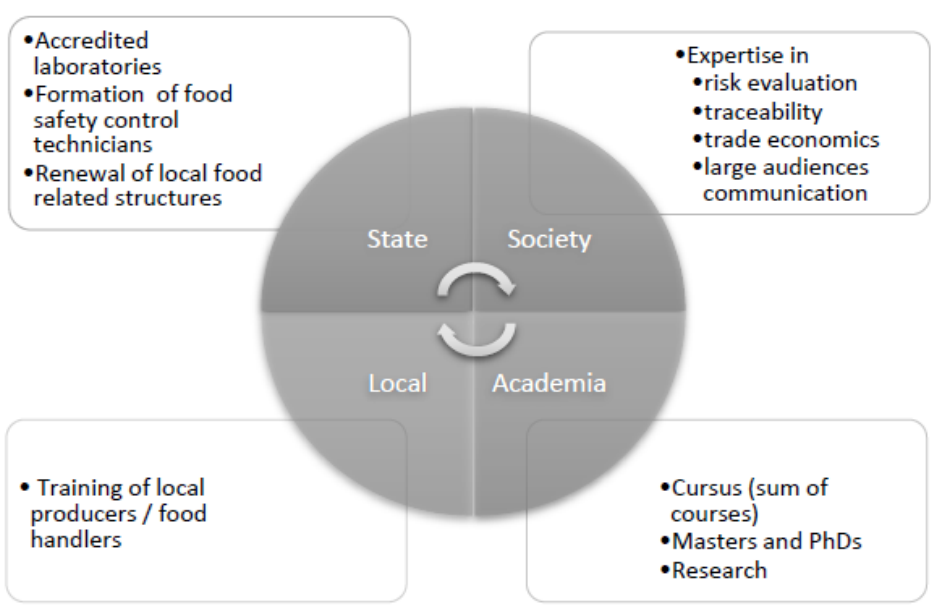

Figure 1. Highlights of the societal areas mitigation measures to face food safety hazards in Morocco

Morocco has a public health system that allows it to see the future serenely despite many challenges in improving food controls. Morocco has also a food safety authority ONSSA that allows it to carry out a food control in the local market and imports. However, consumer exposure to food additives or various chemicals with acceptable daily intake is often too high. The improvement of collective expertise at National level could be a key to prevent crises and to give advices to the government.

\subsubsection{Analysis of Societal Challenges in Food Safety Hazards in Senegal}

The important results obtained from the Dakar collective expertise workshop helped to define the major challenges faced by Senegal in the field of food safety.

The experts' analysis of biological problems (Table 2) in Senegal showed serious hygiene problems, particularly in the areas of artisanal fish, traditional curd, poultry slaughter and water quality sachets.

Chemical hazard analysis emphasizes unmanaged pesticide use in agricultural products, dried fishery products and residues of veterinary drugs in meat and dairy products. Heavy metals are incriminated in the intoxication of the population when consuming fresh fish products or rice contaminated with arsenical derivatives. The presence of mycotoxins in the peanut sector (peanut paste, oil, cakes) or in semi-moist food products is a recurring problem in Senegal, as are Polycyclic Aromatic Hydrocarbons in smoked and braised products.

Table 2. Highlights of biological and chemical problems found by Collective Expertise in Senegal (by alphabetical order and not by degree of risk)

\begin{tabular}{ll}
\hline Biological problems & Chemical problems \\
\hline Aflatoxin in peanut paste, oil, oilcake & Air pollution in street foods \\
Commercialization of water in sachets & Arsenical derivatives in rice \\
Conservation of fresh fruits, & Edible oil packaging and degradation at high \\
vegetables, non-timber forest products & temperature \\
Commercialization of fresh fish and sea & Heavy metals in fresh fish products \\
food & Not allowed packaging \\
Mycotoxins in semi-moist foods & PAH in smoked and braised products \\
Production and slaughter of poultry & Pesticides in dried fishery products and in agricultural \\
& products \\
Post-harvest peanut conservation & Veterinary drug residues in meat and dairy products \\
Traditional curdled milk hygiene & \\
\hline
\end{tabular}

Experts believed that street food must be protected from atmospheric pollution, the risk of intoxication due to the inappropriate use of packaging, and the risks associated with the presence of oil degradation products must be reduced from high-temperature cooking methods, modernize postharvest conservation techniques for peanuts used for oil crushing and control the preservation processes of fresh fruits and vegetables. In addition, certain regulations should be created especially in the field of fresh fish and seafood. 
A summary of the proposal to mitigate food safety problems is presented in Figure 2.

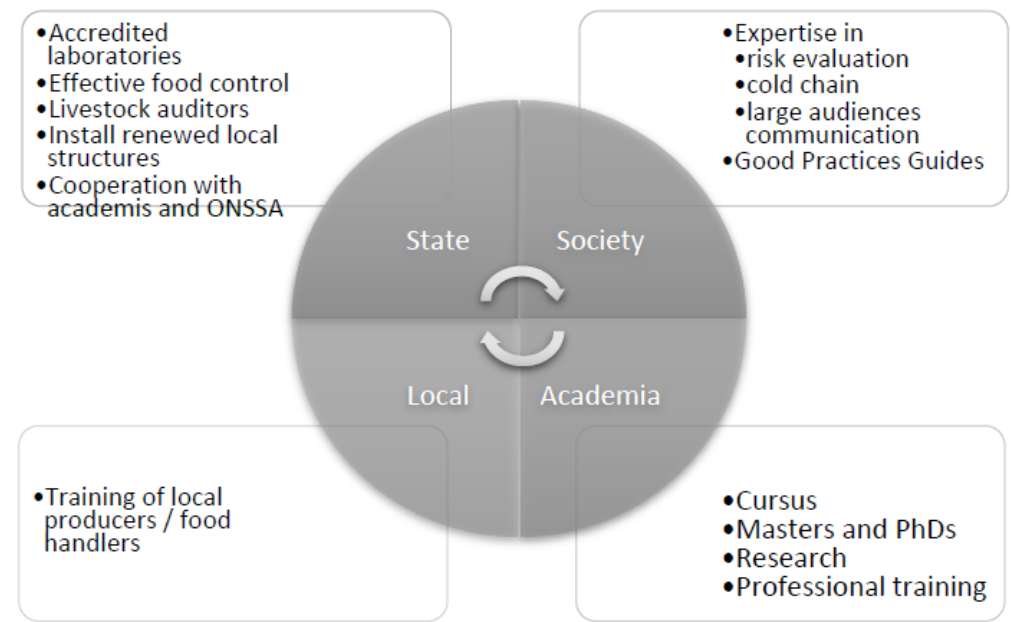

Figure 2. Highlights of the societal areas mitigation measures to face food safety hazards in Senegal

Senegal possess experts in food safety at University level, a well organized team of Codex Alimentarius but they do not have a national authority that could prevent food crisis and help the government to avoid problems.

\subsubsection{Analysis of Societal Challenges in Food Safety Hazards in Democratic Republic of Congo}

The collective expertise workshop conducted in Lubumbashi identified the major challenges faced by the universities involved in the project and their partners in the field of food safety (Table 3). Among the biological hazards identified by the experts, hygiene problems are apparent in all sectors whether at the level of handlers, consumers or food production sites in the DRC. It is essential to improve the production, packaging, transport, storage and sale of traditional foods, including bush meat, traditional beverages and agro-industrial products. The experts proposed to master the conditions of breeding, slaughtering and sale of the meat of the big and small cattle as well as the poultry, to control the chain of production of the local fishing (Rivers and lakes), to improve the conditions of treatment and conservation of cereals and legumes and to control the production and distribution of the products of the picking (mushrooms, insects, fruits, ...).

Table 3. Highlights of biological and chemical problems found by Collective Expertise in DRC (by alphabetical order and not by degree of risk)

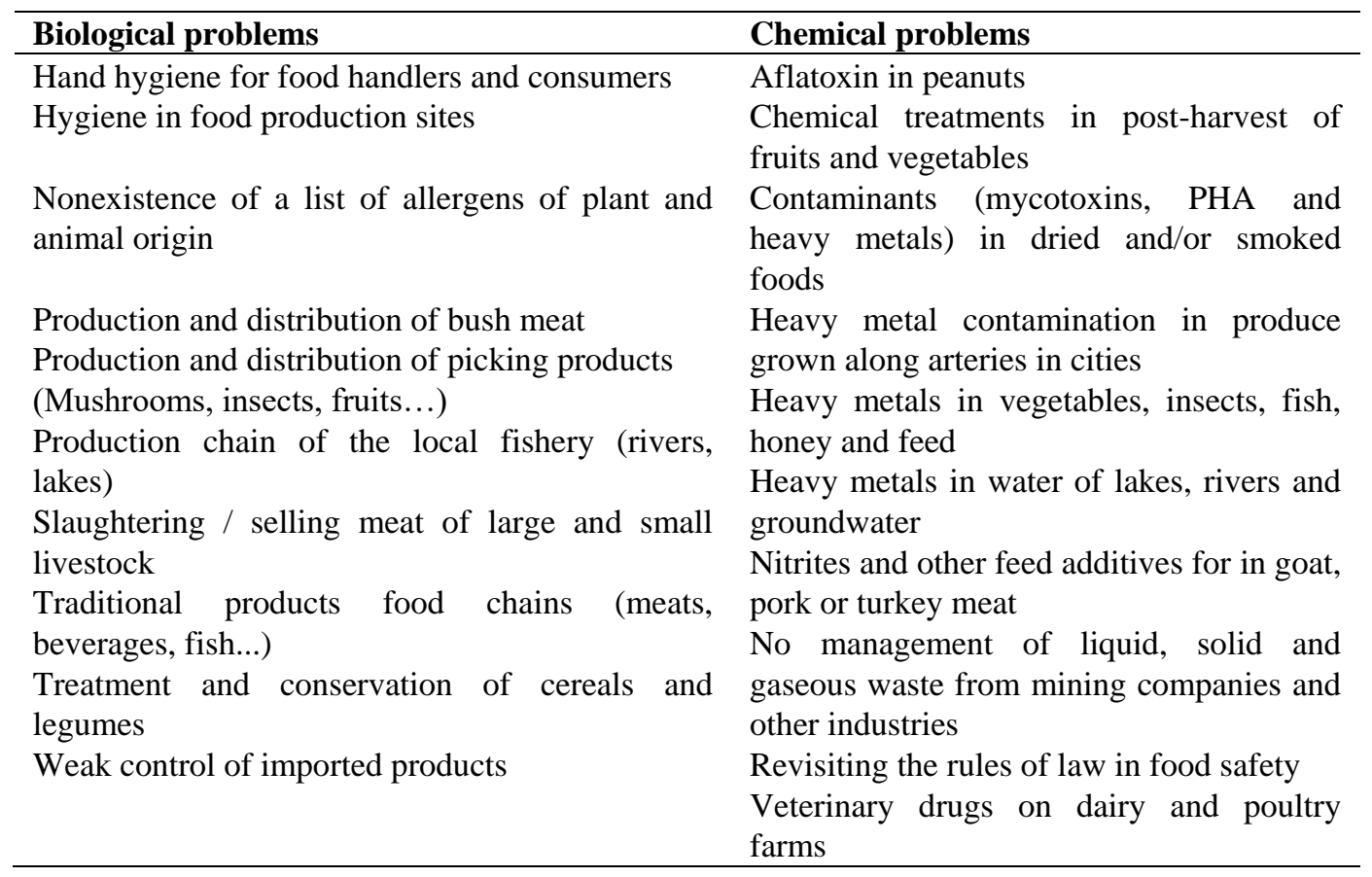


The microbiological hazards were found to be much related to the country habits. Application of practices of basic hygiene was considered as one of the priorities. Poor hygienic quality was encountered both on locally produced food but also on imported food. This was due to the lack of hygiene on the production sites and the hygienic failings on the local markets. There are few food preservation systems and bush meats are out of official control.

The most serious chemical hazard in the DRC identified was linked to the presence of mining effluents and therefore the contamination of agricultural products and food, water (fish) by metallic trace elements (MTE). Fodder contaminated with MTE was incriminated in the contamination of honeys, meat, insects and offal of farm animals. This phenomenon affects $72 \%$ of the region of Upper Katanga. Experts believe that the improvement of this pollution will go through the management of liquid, solid and gaseous waste from mining companies and other industries. Other pollutants from road traffic (gaseous emissions, ores escaping from trucks) also affect market garden produce grown along the major arteries of major cities in the DRC. Dried and/or smoked foods, peanuts are contaminated with mycotoxins and polycyclic aromatic hydrocarbons. The use of pesticides and chemical fertilizers is also poorly controlled. The presence of veterinary residues in food of animal origin is also problematic. The addition of nitrites used as such and not in the form of nitrite salts and other food additives poses a public health problem in goat, pork or poultry meat outlets.

A summary of the proposal to mitigate food safety problems is presented in Figure 3.

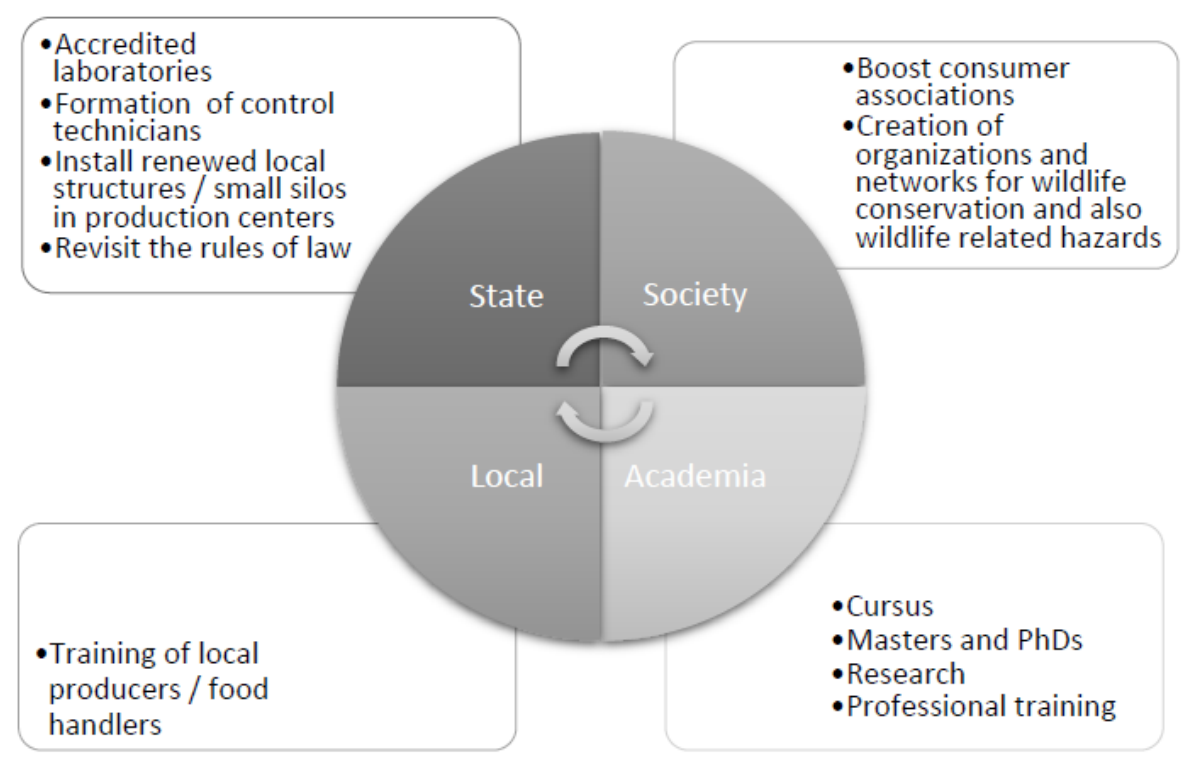

Figure 3. Highlights of the societal areas mitigation measures to face food safety hazards in DRC. Refer to text for further society challenges identified by Collective Expertise

From a more general point of view, experts would find useful to improve the knowledge of Congolese consumers about contaminants in foods. They propose to create an association of consumers and independent laboratories for the realization of counter-expertise to inform the population. It would be desirable to determine the list of allergens of plant and animal origin in the DRC, to improve the control of imported products with respect to microbiological hazards. Not all this can be implemented without revisiting the laws in the area of food safety in the DRC. Moreover, the creation of an observatory of bush meat, of a wildlife disease surveillance and epidemiology network, of a wildlife protection and conservation organizations will be the minimum organisation to face food hazards. Training events for the population on hygiene were still identified as needs for the country as well as update seminars on food safety to small producers, SMEs, lawyers and all potential actors in the food chain.

At this moment, DRC has not a system that will permit to face a food safety crisis. There is a need to improve every level of food safety system as the existence of a control organization, interpretation of the results by experts, prevention of food hazards by expertise, promotion of training for trainees at field level but also for SME. 


\section{Policy Implications}

Theoretically, in a country, the decider in food safety is necessarily a politician elected by the population. Nevertheless, the decisions can then be applied by delegation, as in most of the countries. In general, the delegation consists of entrusting another entity with the task, often the responsibility of the Minister of Agriculture or the Minister of Health, for which those who delegate are ultimately responsible. This choice of delegation, based on the decision of the head of Government, is decisive, and from that choice flows the whole food safety system of a country (Authority, statistics, reference laboratories, official controls, consumer associations...).

A country that does not have this decision-making system is at the mercy of frauds, malfeasance and suffering from pathogens or food contaminants of all kinds. It is not uncommon for a country without sanitary authority to import contaminated products from countries not very interested in the health status of their products. The creation of a food safety system requires a very large and complex expertise that few countries have, but the ones that they have should be utilized for the sake of population health.

\section{Conclusion}

These three workshops, which sought to define, through Collective Expertise, the major challenges faced by the universities of Morocco, Senegal and DR Congo involved in the Erasmus+ project and their partners in the field of food safety allowed to reach important results. The three groups identified food safety challenges in Morocco, Senegal and DR Congo and identified the skills needed to address these challenges. The approach using collective expertise has resulted in the development of 64 challenge cards in a relatively short time. Moreover, the work will also serve to prefigure the construction of university curriculum and research topics in this field.

The observed disparity in the food safety system in these three countries corresponds to their different maturities of their food safety surveillance system. Morocco has already a food safety agency and universities offering training at all levels and professional training in the food sector in the broad sense. Senegal does not have a national safety authority but has created a Codex Alimentarius committee that partially plays the role of a national agency. Universities have courses mainly focused on food technologies and food sciences. It is necessary to adapt existing programs to create real food safety specialists.

The DRC has motivated and competent scientists who practice in different universities or public institutions. This country still needs specialists in food safety and the safety option would be an undeniable plus. The creation of a national committee of experts in this field would enable the government to have informed opinions on the health hazards affecting the population and thus create a capacity to manage the health emergency.

Food control requires financial resources that only Morocco can secure address. Senegal is addressing this problem and the DRC does not have the necessary analytical equipment. The creation of specialized committees of experts using collective expertise would permit to partially overcome these problems.

The training events described in this manuscript for the utilization of Collective Expertise as tool to help decision makers in the area of food safety gave important results that demonstrated that, with a careful and diversified selection of experts, what could be initially seen as an academic exercise, can in fact have a deep importance in these countries. The results obtained can induce changes in university curricula and showed the social impacts of food safety. That study permitted also to develop strategies on research and training needs for the different stakeholders of the food sector and above all will have an impact in food policy in these countries. The collective expertise approach of the determination of hazards also permitted to discuss possible organization models of food risk management in the 3 countries.

\section{Acknowledgements}

This work was supported by the European Union, through the funding of the Erasmus+, Key Action No2, project DAFRALI - "Défis sociétaux et gouvernance des universités AFRicaines: le cas des ALIments au Maroc, en République démocratique du Congo et au Sénégal, No 2015/C 347/06. M.T. Barreto Crespo acknowledges iNOVA4Health Research Unit (LISBOA-01-0145-FEDER-007344), which is co-funded by FCT/MCES, through national funds, and by FEDER under the PT2020 Partnership Agreement.

\section{References}

Montet, D., Hazm, J. E., Ouadia, A., Chichi, A., Mbaye, M. S., ... Barreto Crespo, M. T. (2019). Contribution of the methodology of Collective Expertise to the mitigation of food safety hazards in low-or medium-income countries. Food Control, 99, 84-88. https://doi.org/10.1016/j.foodcont.2018.12.009

Montet, D., Shobaky, A. A., Barreto Crespo, M. T., Payrastre, L., Mansour, H., ... Mohamed, S. (2015). Future 
topics of common interest for EU and Egypt in food quality, safety and traceability. Quality Assurance and Safety Crops \& Foods, 7(3), 401-408. https://doi.org/10.3920/QAS2014.0428

Montet, D., Alldrick, A., Bordier, M., Bresson, H., Chokesajjawatee, N., ... Saletes, S. (2010). Identification of topics of common interest for EU and SEA partners in the thematic "Food Quality, Safety and Traceability" towards a strengthening of Science and Technology collaboration between SE Asia and EU in the FP7 programmes. EU-Southeast Asia Expert meeting on Food Quality, Safety \& Traceability. Bangkok, Thailand - 24-27 February 2009. Quality Assurance and Safety of Crops \& Foods, 2(4), 158-164. https://doi.org/10.1111/j.1757-837X.2010.00078.x

Morocco (2009). Law No. 25-08 establishing the National Office for Food Safety (ONSSA), promulgated by the Dahir No. 1-09-20 of 22 Safar 1430 (February 18, 2009). BO No. 5714 of 05/03/2009, p. 358. Retrieved from http://www.onssa.gov.ma/fr/images/reglementation/transversale/LOI.25-08.FR.pdf

Morocco (2010). Law No. 28-07 on the safety of food products, promulgated by the Dahir No. 1-10-08 of 26 Safar 1431 (February 11, 2010). BO 5822 of 18/03/2010, page 214. Retrieved from http://www.onssa.gov.ma/fr/images/Publications/loissaetdecretarfr.pdf

OMS (2007). Food Safety and Health: A Strategy for the WHO African Region, Regional Committee for Africa, Fifty-seventh Session Brazzaville, Republic of Congo, 27-31 August 2007, p. 10. Retrieved from https://apps.who.int/iris/handle/10665/1817

DRC (2005). Decree No 05/162 of 18 November 2005 on phytosanitary regulations in the Democratic Republic of Congo. Retrieved from http://cd.chm-cbd.net/implementation/fol320521/plugin-cd_decret_reglementation_phytosanitaire

DRC (2009). Decree No. 09/44 of 03 December 2009 laying down the statutes of a public institution of a scientific and technical nature called the Congolese Office of Control (OCC). Retrieved from https://www.leganet.cd/Legislation/Droit\%20Public/Etablissements/DeCRET.09.44.03.12.2009.pdf

Senegal (1966). Law No. 66-48 of 27 May 1966 on the control of food products and the repression of fraud. Retrieved from http://extwprlegs1.fao.org/docs/pdf/Sen174045.pdf

Senegal (1983a). Law No. 83-71 of 5 July 1983 on the Code of Hygiene. Retrieved from https://ordredesavocats.sn/loi-n83-71-du-5-juillet-1983-portant-code-de-lhygiene/

Senegal (1983b). Decree 83-1204 of November 22, 1983, establishing the National Committee of the Codex Alimentarius. Retrieved from https://www.pressafrik.com/Comite-National-du-Codex-Alimentarius-Reunir-tous-les-acteurs-afin-de-prote ger-et-assurer-les-pratiques-via-OMS-et-FAO_a123878.html

\section{Copyrights}

Copyright for this article is retained by the author(s), with first publication rights granted to the journal.

This is an open-access article distributed under the terms and conditions of the Creative Commons Attribution license (http://creativecommons.org/licenses/by/4.0/). 